Portland State University

PDXScholar

$1-1-2020$

\title{
The Adolescent Peer System and Academic Engagement
}

\author{
Carrie Jeanne Furrer \\ Portland State University, cfurrer@pdx.edu \\ Gwen Catherine Marchand \\ Portland State University
}

Follow this and additional works at: https://pdxscholar.library.pdx.edu/childfamily_pub

Part of the Family, Life Course, and Society Commons

Let us know how access to this document benefits you.

\section{Citation Details}

Furrer, C. J., \& Marchand, G. C. (2020). The adolescent peer system and academic engagement. Educational Psychology, 1-20.

This Post-Print is brought to you for free and open access. It has been accepted for inclusion in Center for Improvement of Child and Family Services Publications by an authorized administrator of PDXScholar. Please contact us if we can make this document more accessible: pdxscholar@pdx.edu. 


\title{
Running Head: ADOLESCENT PEER SYSTEM
}

The Adolescent Peer System and Academic Engagement

\author{
Carrie J. Furrer ${ }^{*}$ and Gwen C. Marchand ${ }^{\mathrm{b}}$ \\ ${ }^{a}$ Center for Improvement of Child \& Family Services, Portland State University, Portland, \\ United States; ${ }^{\mathrm{b}}$ Department of Educational Psychology \& Higher Education, University of \\ Nevada - Las Vegas, Las Vegas, United States
}

* Corresponding author: Carrie J. Furrer, Portland State University, PO Box 751 - CCF, Portland, OR 97207, cfurrer@pdx.edu, office (503)725-2138, fax (503)725-2140 


\begin{abstract}
Peers are central in shaping adolescents' development across various domains. This research examined patterns of peer system resources and liabilities, and their association with academic adjustment. A person-centred approach, Latent Profile Analysis, was used to classify students into groups based on characteristics of the peer system: friendship quality, group, and general peer relations. Participants were 443 students in their ninth grade year, 14 years old on average, and $57 \%$ female. Peer system characteristics formed four profiles. The most common profile had high resources and low liabilities; the three other profiles were mixtures of moderate/high resources and low/moderate liabilities. Students with high resources/low liabilities had higher self- and teacher-reported academic engagement and GPA in fall and spring. The three mixed profiles were associated with poorer academic outcomes. These findings underscore the limitations on access to academic success for students negotiating different peer contexts.
\end{abstract}

Key words: Peers; peer system; social context; adolescent; academic engagement 
Peers become increasingly important for adolescents and are a key context for shaping well-being. Peers constitute a social system (or 'peer system') with embedded levels of complexity including individuals, social exchanges, relationships, groups, relations with the larger peer group, and culture (Rubin, Bukowski, \& Parker, 2006). Components of the peer system and their associations with childhood well-being have been largely explored in separate literatures. Although there is recognition that the peer system has multiple characteristics existing within various levels of social organisation, theory and research has only recently begun to explore the multiple ways that adolescent peer systems contribute to academic achievement and psychological factors related to learning in school, such as student motivation, collectively referred to as academic adjustment (Zee \& Koomen, 2016).

A large body of research has identified predictors of academic achievement and its proximal predictor, engagement (for examples see Fredricks, Blumenfeld, \& Paris, 2004; Skinner, Furrer, Marchand, \& Kindermann, 2008). Less attention has been paid to understanding the role of peers in academic adjustment, but they are widely considered a central factor (Ryan, 2001). The interface between peers and academic adjustment is not straightforward. Research shows that peers promote academic adjustment by supporting positive emotions and self-beliefs (e.g., belonging, self-efficacy, goal orientation) (Martin \& Dowson, 2009; Wentzel, 1999). Peers offer instrumental and psychological resources by providing social capital (Crosnoe, Cavanagh, \& Elder, 2003). Bullying, coercion, modelling antisocial behaviour, and engaging with antisocial peers can also undermine academic adjustment (Dishion \& Tipsord, 2011; Wang \& Eccles, 2012).

The goal of this research is to examine within-person configurations of peer system characteristics and their association with academic adjustment. Taking a person-centred 
approach (von Eye \& Bogat, 2006), this study identified distinct profiles characterizing students' perceptions of their peer system at three levels (friendship quality, group, and general peer relations) and associated academic outcomes.

\section{Peer System as a Developmental Context}

Peers form a critical developmental context for adolescents (Furrer, 2010; Ryan, 2001). As adolescents increasingly spend time with peers, their relationships become more supportive and intimate (Bagwell \& Schmidt, 2013). Adolescents select their friends, are influenced by their friends, and shape their friendships over time (Popp, Laursen, Kerr, Stattin, \& Burk, 2008). Drawing from ecological systems theory (Bronfenbrenner \& Morris, 1998), the peer system has been conceptualised various ways. Rubin and colleagues (2006) suggested four levels of increasing social complexity: interactions, relationships, groups, and culture. La Greca and Harrison (2005) outlined three levels of adolescent interpersonal functioning: general peer relations (crowd affiliation, victimisation), best friendships, and romantic relationships. This study borrows from these conceptualisations to arrive at three levels of the peer system: friendship quality, group, and general peer relations.

Friendship quality. Friends spend time talking and listening to each other, creating a sense of belonging and care (Parker \& Asher, 1993). Adolescents with supportive friendships feel more competent at school, are more involved in classroom activities, and have higher academic achievement (Martin \& Dowson, 2009; Wentzel, Barry, \& Caldwell, 2004). High quality friendships are associated with school competence, classroom involvement, and achievement (Kindermann, 2007; Kurdek \& Sinclair, 2000). Feeling connected to peers is related to academic engagement (Furrer \& Skinner, 2003; Juvonen, Espinoza, \& Knifsend, 2012), whereas peer rejection and loneliness are linked to lower participation and interest in school, 
lower grades, and dropout (Bellmore, 2011; French \& Conrad, 2001; Wentzel, 1999).

Controlling friends can undermine academic engagement, motivation, and positive well-being (Hawley, Little, \& Pasupathi, 2002; Legault, Green-Demers, \& Pelletier, 2006). Thus, supportive friendships are resources, and controlling friendships are liabilities, for academic adjustment.

\section{Group}

Friendship groups have unique characteristics including size, perceived social power, and group behaviours.

Friendship network size. Number of friends influences involvement in school. Students with fewer friends had lower school involvement before the transition to middle school and in sixth grade (Kingery \& Erdley, 2007). A larger number of friends could increase social support, improve one's sense of social competence, or reflect one's own social skill (Juvonen et al., 2012). Having at least one reciprocated friendship was associated with higher academic motivation and lower likelihood of high school dropout (Ricard \& Pelletier, 2016). Consequently, friendship network size is likely a resource for academic adjustment.

Group power. Social power can be explicit and aggressive, eliciting fear, submission, or compliance. Another form is implicit, or a referent approach based on group assets valued by others (La Freniere \& Charlesworth, 1983). According to Rubin et al. (2006), “...the main rewards that can be provided at the level of the group are power, attention, and status (p. 599)." It is likely that referent power, which is related to social assets (Lease, Kennedy, \& Axelrod, 2002), is a resource, and that fear power, which is related to aggression (Vaillancourt, Hymel, \& McDougall, 2003), is a liability in the school setting.

Friend involvement in problem behaviour. Affiliating with friends involved in problem behaviours (e.g., substance use) has been shown to reduce school connectedness 
(Dishion \& Tipsord, 2011), leading to school disengagement and dropout (French \& Conrad, 2001). Thus, associating with friends involved in problem behaviours is likely an academic liability.

\section{General Peer Relations}

Although aggression and victimisation typically refer to an individual, they reflect general relations with peers in the school context (La Greca \& Harrison, 2005). Individual and peer group aggression have been linked to poorer academic adjustment (Chung-Hall \& Chen, 2009; Loveland, Lounsbury, Welsch, \& Buboltz, 2007). Adolescents who are victimised at school tend to have poorer academic adjustment due to negative self-perceptions, peer rejection, and diminished school belonging (Espelage, Hong, Rao, \& Low, 2013; Nakamoto \& Schwartz, 2010). Both aggression and victimisation are likely academic liabilities.

\section{Complexity of the Peer System}

Individual characteristics do not capture the complexity of the peer system. Variablecentred methods (e.g., moderation) examine interactive effects between characteristics. For example, affiliation with friends involved in delinquent behaviour, typically viewed as a liability, had no influence on school attachment when friendship quality was high (Boman, Krohn, Gibson, \& Stogner, 2012). As another example, victimisation had a negative effect on academic functioning, but only when children had a high or low number of aggressive friends (Schwartz, Gorman, Dodge, Pettit, \& Bates, 2008). Thus, peer systems shape multiple pathways to academic adjustment through resources and liabilities that interact in unexpected ways.

A person-centred approach focuses on configurations of characteristics (Kretschmer et al., 2016; Scholte, van Lieshout, \& van Aken, 2001). This study explored whether perceived peer system characteristics clustered into profiles with different patterns of academic adjustment. It 
was hypothesised that there would be at least three profiles: high resource/low liability, low resource/high liability, and mixed resource/liability. A high resource/low liability peer system would have high quality friendships, larger friendship networks with referent power, and low friend involvement in problem behaviour, aggression, and victimisation. In contrast, a low resource/high liability peer system would be marked by poor friendship quality, fear power, friends involved in problem behaviours, and more aggression and victimisation. At least one mixed quality profile was also expected (Smith, Ullruch-French, Walker II, \& Hurley, 2006). Certain peers are more competent at meeting needs than others, peers may be complementary, and power dynamics arise within friendships (Rubin, Fredstrom, \& Bowker, 2008). One possible combination is moderate resource/moderate liability, in which students have fewer friends, some fear power and friend involvement in problem behaviour, but also perceived high quality friendships.

Student gender and race were included as predictors of profile membership. Research has shown that peer system characteristics and their associations with academic adjustment differ according to gender and race. Girls report higher prosocial behaviour, more time spent creating intimate relationships with friends, and less direct aggressive than boys (Perry \& Pauletti, 2011; Rose \& Rudolph, 2006). Students experience peer relationships at school, social support, and school belonging differently based on racial/ethnic identity (Faircloth \& Hamm, 2005; Matthews, Banerjee, \& Lauermann, 2014). For example, stigmatized interactions at school may result in fewer opportunities for minoritised males, in particular, to experience positive relationships within the school context (Gray, Hope, \& Matthews, 2018).

\section{Academic Adjustment}


Two indicators of academic adjustment from three informants were studied: classroom engagement and grade point average (GPA). Classroom engagement predicts learning and achievement, high school graduation, and college entry (Fredricks et al., 2004). Engagement is a resource for managing academic challenges and it facilitates motivational resilience (Furrer, Skinner, \& Pitzer, 2014; Martin \& Marsh, 2009). Two dimensions of engagement, behaviour and emotion, were examined. The behavioural dimension focuses on active participation, effort, and persistence in learning activities, whereas and the emotional dimension gauges interest and enjoyment (Skinner, Kindermann, \& Furrer, 2009).

Classroom engagement was evaluated using student and teacher reports. An engaged state is highly salient, so students are considered the best reporters of their own engagement (Skinner et al., 2009). Teachers regularly interact with students and can provide a good assessment of engagement, but perhaps they are more sensitive to observed aspects if students are masking emotional states like boredom or anxiety. Cumulative GPA was another marker of academic adjustment. Although GPA is often viewed as unreliable due to differences grading standards, research suggests that GPA has strong predictive validity in terms of college success (Geiser \& Santelices, 2007).

It was hypothesised that the high resource/low liability profile would have the highest, and the low resource/high liability profile would have the lowest, engagement and GPA. It was also expected that mixed quality profiles would have moderate academic adjustment. Due to the lack of previous research on profile membership based on perceptions of the peer system, we did not hypothesize specific differences for gender and race/ethnicity.

\section{Methods}

\section{Participants}


Students were recruited from a ninth grade career selection class $(n=655)$ at a suburban high school $\left(9^{\text {th }}-12^{\text {th }}\right.$ grade) in Northwestern United States. The class was taught by seven teachers. The sample included 443 students (68\% of those enrolled in the class), 57\% girls and 14.7 years old on average. Nearly two-thirds (64\%) of the students were white, and one-third identified as Latinx (14\%), Asian/Pacific Islander (10\%), Multiracial (7\%), African-American (5\%), and American Indian/Native American (1\%).

\section{Measures}

Descriptive and reliability statistics are provided in Table 1.

Background. Students reported their gender (male/female) and race (White, Black, Hispanic, Asian/Pacific Islander, American Indian/Native American, and Other). Age at time of assessment was calculated from date of birth.

Friendship quality. Two friendship quality scales, Supportive and Controlling, were constructed using exploratory factor analysis with principal axis factoring and oblique rotation. Fourteen items split evenly into two dimensions with no cross-loadings $>.30$, accounting for $42.4 \%$ of the variation in the data. The Supportive scale had factor loadings ranging from .53 to .87 (My friends... 'listen to me,' 'understand me'). The Controlling scale had factor loadings ranging from .45 to .63 (My friends... 'try to control what I do,' 'tell me what to do'). Scale scores were calculated by averaging item responses (1=not at all true for me to 4=totally true for $m e)$.

\section{[Table 1 near here]}

Friendship group power. The average of two self-reported items (1=not at all true for us to 4=totally true for us) formed the Referent Power scale: 'Other kids want to be like people in our group' and 'Other kids want to be in our group.' Similarly, the Fear Power scale was 
calculated by averaging responses to three items: 'Our group can get kids to do whatever we want,' 'Adults at school do not like our group,' and 'Other kids are afraid of our group.'

Aggression and victimisation. Aggression was measured using an 11-item self-report measure of frequency of behaviours (e.g., "I fought back when someone hit me first," "I pushed or shoved other students") (Aggression Scale, Orpinas \& Frankowski, 2001). Victimisation was measured with an 8-item measure assessing how often students were bullied over the past month (e.g., "Someone threatened me," "Someone laughed at me in a mean way") (Boulton, Trueman, \& Flemington, 2002). Aggression and victimisation scales were calculated by averaging responses for each item $(0=$ never to $4=$ all of the time $)$.

Friend involvement in problem behaviour. Students indicated how many of their friends were involved in 12 different behaviours $(0=$ none to $4=$ almost all $)$ such as substance use and stealing, and athletics and school (reverse-coded). Ratings were averaged to create an overall problem behaviour score.

Friendship network size. Students nominated an unlimited number of same-grade friends at school (spent the most time, knew the best). A nomination was reciprocal if the student was also nominated by their friend. Of the 443 participants, $376(85 \%)$ nominated at least one friend who participated in the study, $15(3 \%)$ nominated students who did not participate in the study, $6(1 \%)$ did not nominate any friends, and $46(10 \%)$ did not complete the assessment. Of the 376 who nominated friends, $335(89 \%)$ had at least one reciprocated nomination $(76 \%$ of the sample).

Classroom engagement. Students reported on their classroom engagement using Wellborn's (1991) 20-item scale evenly split between behavioural (e.g., 'When we start something new in class, I participate') and emotional items (e.g., 'When we start something new 
in class, I feel worried' [reverse-coded]). Teachers also rated 13 items about their students' behavioural and emotional engagement (Wellborn, 1991). To reduce workload, teachers completed the measure for a random subset of students $(n=245)$. Scales for behavioural and emotional engagement were computed for each reporter by reverse-scoring disaffection items and averaging responses $(1=$ totally not true to $4=$ totally true $)$.

Grade point average. The Human Subjects Review Board required that students could opt out of the administrative data collection. A subset of 148 students consented to the extraction of their first semester and cumulative GPA (4.0 scale) from administrative records.

\section{Data Analysis}

To investigate group classification based on peer system characteristics, a series of mixture models were conducted using Mplus v7.0 (Muthén \& Muthén, 1998-2011). Missing data were handled using MLR (maximum likelihood robust) estimation for non-normal data (see Yuan \& Bentler, 2000). This approach assumes that data are missing at random (MAR), or the probability of nonresponse on one or more variables is associated with other observed variables (Collins, Schafer, \& Kam, 2001). Missing data for this study was mostly teacher-reported engagement and GPA, which were correlated with other variables in the model.

Latent Profile Analysis (LPA) classified students into groups based on peer system characteristics: supportive and controlling friendship quality, friendship network size, referent and fear power, friend involvement in problem behaviour, aggression, and victimisation. Models included race (student of colour/not) and gender (male/female) as predictors. LPA classifies individuals based on the covariances of a set of observed dependent variables, or latent class indicators (Marsh, Lüdtke, Trautwein \& Morin, 2009). In contrast to other person-centred approaches like cluster-analysis, LPA directly tests competing models with differing numbers of 
classes. Whereas cluster analysis assigns individuals to a particular class, LPA accounts for the uncertainty of classification by determining the probability of being assigned to each class.

The 3-step method (Asparouhov \& Muthén, 2012) was used to determine number of classes. After identifying the optimal log-likelihood value using random starting values, model fit comparison was assessed using the Lo-Mendell-Rubin likelihood ratio test (LMR; Lo, Mendell, \& Rubin, 2001). Significantly smaller log-likelihood values reject the $k-1$ class model in favour of the $k$ class model. The last step compares models using the bootstrap likelihood ratio test (BLRT; Nylund, Asparouhov \& Muthén, 2007). The models were also evaluated on the basis of Akaike information criteria (AIC) and Bayesian information criteria (BIC) fit indices, and entropy values, a measure of differentiation among classes. Classes were then differentiated by academic adjustment using the Auxiliary (DESTEP) function, which tests for the equality of means on variables external to LPA classification using posterior probabilities to calculate a Wald chi-square statistic (Asparouhov \& Muthén, 2013; Chen, 2012).

\section{Results}

\section{Descriptives}

Students reported having supportive friendships and low levels of friend involvement in problem behaviour, aggression, and victimisation (see Table 1). Friendship networks contained three friends on average. Fear power was low, but students reported moderate levels of referent power. Both students and teachers reported moderately high classroom behavioural and emotional engagement. Correlations were moderate and in the expected direction. Peer system resources (supportive friendship quality and friendship network size) were positively correlated with at least one academic outcome. Referent power was not significantly associated with 
academic outcomes, but it was positively correlated with the other resources. Peer system liabilities were all negatively correlated with at least one academic outcome.

\section{Latent Profiles}

Table 2 depicts the goodness-of-fit indices for models with two through six latent profiles. The four-profile solution offered a strong distinction among the classes, with an entropy level of .85 (see Figure 1). High resource/low liability (HR/LL) was the most common profile, with $63 \%$ ( $n=279$ ) of students in this group. The probability of correct classification (PCC) for HR/LL was $95 \%$. There was not a low resource/high liability profile as hypothesised, but there were three less common mixed profiles. One in five participants were categorised as high resource/medium liability $(\mathrm{HR} / \mathrm{ML} ; 21 \%, n=92, \mathrm{PCC}=83 \%)$. There was also a medium resource/high liability $(\mathrm{MR} / \mathrm{HL})$ profile $(9 \%, n=41, \mathrm{PCC}=87 \%)$, and a low resource/medium liability (LR/ML) profile comprising only $7 \%$ of participants $(n=29, \mathrm{PCC}=87 \%)$. A significantly larger share of girls had the most common HR/LL profile, and a larger share of boys had the MR/HL profile $(O R=2.96, p<.05)$. Students of colour were marginally less likely to have the HR/LL and LR/ML profiles, and more likely to have the MR/HL profile ( $O R=2.06$ and $O R=3.06$, respectively, $p<.10$ ).

[Table 2 near here]

[Figure 1 near here]

Table 3 shows differences between the four profiles on peer system characteristics. HR/LL distinguished itself from the other three profiles by having the most positive general peer relations (lowest aggression and victimisation) and the lowest friend involvement in problem behaviour. Students with this profile also reported high supportive and low controlling friendship quality, and group characteristics typical of popularity (larger friendship network, moderate 
referent and low fear power). This profile was labelled the Dominant peer system at this school, and it was most similar to the school in terms of gender and race.

[Table 3 near here]

HR/ML was the next largest profile, and uniquely had moderate fear power and victimisation. These students were not significantly different from Dominant on friendship quality and friendship network size, but had group characteristics and general peer relations that suggested some challenge (high referent power, moderate friend involvement in problem behaviour and aggression). This profile was labelled Signs of Challenging Peer Relations (abbreviated to 'Signs').

Another less common peer system profile, MR/HL, had the most challenging group characteristics and relations with peers (high fear power, friend involvement in problem behaviour, aggression, and victimisation) combined with moderately supportive and controlling friendship quality. These students also reported a smaller friendship network and higher referent power (not significantly different than Dominant and Signs). This profile was labelled Most Challenging Peer Relations (abbreviated to 'Most').

Students with the least common profile, LR/ML, had the least supportive friendships and the lowest referent power along with a mixture of peer system liabilities. Like Most, they reported having controlling friends and a high degree of victimisation. Similar to Dominant, these students reported low fear power, and similar to Signs, they had moderate friend involvement with problem behaviour and aggression. This profile was named Low Friend Quality, Some Challenging Peer Relations (abbreviated to 'Low, Some').

\section{Academic Adjustment}


As hypothesised, the most common peer system profile, Dominant, was associated with the highest student- and teacher-reported engagement and GPA in fall (see Table 4). Academic outcomes for Signs were significantly poorer than Dominant, significantly better than Most (except for student-reported emotional engagement), and similar to Low, Some. Contrary to expectations, Most had the poorest student- and teacher-reported behavioural engagement, and lower teacher-reported emotional engagement and GPA (not statistically different than Low, Some).

\section{[Table 4 near here]}

Academic adjustment patterns became more homogenous in spring. Dominant continued to have the best academic outcomes, although teacher-reported emotional engagement only differed significantly from Signs. The three other profiles looked similar in terms of student- and teacher-reported behavioural engagement, and student-reported emotional engagement. Most showed some improvement in academic adjustment, with teacher-reported behavioural and emotional engagement and GPA improving by approximately a half of a scale point. The between-profile differences found for fall GPA persisted in spring despite the fact that Low, Some and Most no longer had the poorest engagement.

\section{Discussion}

The peer system is a critical developmental context for adolescents. The current study endeavoured to understand whether the peer system reflects multiple developmental pathways to academic adjustment through the provision of resources and liabilities. Four distinct peer system profiles were found. Supporting the hypothesis that the most common profile would have high resources and low liabilities, Dominant had the most 'desirable' characteristics at all three levels of the peer system: high friendship quality, larger group size, feelings that others wanted be like 
them and not fear them, and little experience with problem behaviours, aggression, and victimisation. Dominant had a higher proportion of girls and white students, and it was associated with the most positive pattern of academic outcomes in both fall and spring.

There were also three less common profiles with mixtures of resources and liabilities and lower academic adjustment; however, there was not a low resource, high liability profile with the worst academic adjustment. The Signs profile was similar to Dominant in terms of friendship quality and friendship network size, but these students also faced challenges with problem behaviour, aggression, and victimisation. They were similar to Most in feeling that other students wanted to be like them but also feared them. Signs had both positive and negative peer system characteristics, a finding consistent with bistrategic friendships that are both coercive and prosocial (Hawley, Little, \& Card, 2007). Signs had modest academic adjustment across all indicators, suggesting that peer system challenges may have undermined academic adjustment despite higher quality friendships, contrary to evidence of the buffering effect of friendship quality (e.g., Boman et al., 2012).

The Low, Some profile had the poorest friendship quality, low feelings of power, higher victimisation, and moderate friend involvement in problem behaviour and aggression. Victimisation has been linked to both poor friendship quality (Bollmer, Milich, Harris, \& Maras, 2005) and lower academic performance (Espelage et al., 2013), especially if also involved in disruptive behaviours (Beran, 2009). Low, Some were similar in academic adjustment to Signs, but they were also similar to Most in terms of teacher-reported emotional engagement and GPA. Perhaps teachers view victimised students as being unhappy or weak (Fox \& Boulton, 2005), attributes that may also influence teachers' perceptions of student engagement and performance. 
The Most profile, more likely to be boys and students of colour, had high fear power, small friendship networks, and higher levels of peer problem behaviours, aggression, and victimisation. Most was closest to the hypothesised low resource, high liability profile but these students reported moderate resources in terms of friendship quality and referent power. Previous research has also shown that students involved in delinquent behavior perceive the quality of their friendships similarly to students not involved in delinquent behavior (Selfhout, Branje, \& Meeus, 2008; Vaillancourt et al., 2003). Most had the lowest fall behavioural engagement, and low teacher-reported emotional engagement and GPA. It is noteworthy that Most had higher teacher-reported engagement and GPA in the spring, and did not differ significantly from the other mixed profiles on self-reported engagement. It is possible that the transition to high school may have been difficult for Most and they improved over time. Alternatively, perhaps teachers initially made inferences about academic engagement based on students' behaviour, but over the school year they used relational information to make such observations.

\section{Configurations of Resources and Liabilities}

Resources and liabilities are one organising principle for research on the peer system, but the current study suggests a more complex picture. Peer system resources did not necessarily protect students from the influence liabilities had on academic outcomes. However, students with power and aggression may have other assets valued by teachers and peers (Vaillancourt et al., 2003), and therefore might be viewed as more engaged at school. Nevertheless, students with mixed profiles had more academic challenges than students with the Dominant profile, suggesting that liabilities are functionally equivalent when it comes to the school environment. Narrow definitions of 'acceptable' school behavior can serve to marginalise students associated with any type of peer system liability (Osborne, 1996) and the harmful effects seem to exert 
more influence on academic adjustment than the beneficial effects of the peer system resources (see Baumeister et al., 2001) .

Findings suggest one dominant path afforded by the peer system to greater academic adjustment, and multiple pathways to poorer academic adjustment. As students adapt to conditions at school, they may use aggression and coercion in place of, or in addition to, more 'normalised' prosocial strategies (Bjorkland \& Hawley, 2014). If the dominant path is less accessible, students may take on liabilities in response to a lack of access to resources. Therefore, the generalisability of specific profiles may be less important than the notion that there is a dominant path and a number of less common paths. The utility of understanding the less common paths, which would differ according to context, is the degree of teachers' attunement to them and their ability to respond with support (Farmer, Lines, \& Hamm, 2011).

\section{Role of Race and Gender}

Although there were not specific hypotheses regarding race and gender, it is noteworthy that Dominant was more likely to include white girls, whereas Most was disproportionately males of colour. In contrast to Most, Dominant faced the fewest peer system challenges and performed what may be 'normalised' behavior at school and with friends. This is consistent with research showing that girls report more typically prosocial and self-regulated behavior (Perry \& Pauletti, 2011; Rose \& Rudolph, 2006). It also aligns with research suggesting that minoritised males face stigma about their social groups that may lead to alienation from school, fewer positive teacher relationships, and lack of access to curriculum that capitalises on their cultural heritage (Gray et al., 2018; Taylor \& Graham, 2007). Repeated exposure to stigmatised interactions and harsh discipline policies may leave boys particularly vulnerable to motivational and academic challenges (Taylor \& Graham, 2007). 


\section{Limitations and Future Directions}

Survey administration occurred on a school day in a particular class, thereby excluding students who were absent or not enrolled in the class. Students were able to decline participation in the administrative data collection. Those who declined reported a significantly smaller friendship network; more friend involvement in problem behaviour, aggression, and victimisation; higher fear power; and lower behavioural engagement. However, missing data were handled with MLR estimation, which reduces the likelihood that parameter estimates were biased (Allison, 2009). Another issue is the nested data structure was not accounted for in the models due to the small number of teachers $(n=7)$, which could have led to underestimates of standard errors. Future studies with a larger number of clusters should adjust for cluster correlated data to reduce the likelihood of Type 1 errors.

Data were collected in fall and spring but analysed concurrently so it is not possible to infer causality or change over time. A next step is to examine changes in peer system profiles and their association with different developmental trajectories. Most of the measures were selfreported, which could have led to inflated correlations. Self-perceptions are probably best captured with self-reports, but the peer system could also be assessed through observations or other reporters, or by using qualitative methods (DeCuir-Gunby \& Schutz, 2014; Usher, 2018).

The majority of white students in this study possibly obscured the identification of profiles specific to minoritised students (Matthews, 2014). It is also possible that the measures centred white student experiences and lacked relevance to students of colour (DeCuir-Gunby \& Schutz, 2014). Replicating this study with specific student populations would provide a more accurate understanding of peer systems and academic adjustment for students who are not members of a privileged group. Finally, additional research is needed on how culture influences 
the development of peer systems (Rubin et al., 2008) and the impact of school environments that do not value students' heritage (Meece, Glienke, \& Askew, 2009).

\section{Implications}

Peer systems reflect opportunities and liabilities afforded by the school context. With multiple types of peer systems associated with poorer academic adjustment, it is important that schools work to broaden 'normalised' social structures by creating more opportunities in the classroom. Teachers attuned to peer systems can manage the classroom social context to promote a positive culture and support marginalised students (Farmer et al., 2011). Some school-based interventions focus on creating positive relationships between students and shared learning, especially through mixed group interactions and collaborative learning tasks with students outside their gender, racial, or cultural groups (Chen \& Graham, 2015; Gillies, 2003; Slavich \& Zimbardo, 2012). Culturally responsive pedagogy shows promise for reducing classroom management practices that marginalise students and promoting engagement (e.g., Bradshaw et al., 2018). Finally, multi-systemic approaches, in which communities, staff, parents, and students co-create classroom contexts that support positive behaviour, also show positive impacts on students' academic adjustment (Durlak, Weissberg, Dymnicki, Taylor, \& Schellinger, 2011). 


\section{References}

Allison, P. D. (2009). Missing data. In A. Maydeu-Olivares \& R. E. Millsap (Eds.), The SAGE Handbook of Quantitative Methods in Psychology (pp. 72-89). Thousand Oaks, CA: Sage.

Asparouhov, T., \& Muthén, B. (2012). Using Mplus TECH11 and TECH14 to test the number of latent classes [PDF file]. Mplus Web Notes, 14. Retrieved from https://www.statmodel.com/examples/webnotes/webnote14.pdf

Asparouhov, T., \& Muthén, B. (2013). Auxiliary variables in mixture modeling: 3-step approaches using Mplus. Mplus web notes, 15, 1-24.

Bagwell, C. L., \& Schmidt, M. E. (2013). Friendships in childhood and adolescence. New York: Guilford.

Bellmore, A. (2011). Peer rejection and unpopularity: Associations with GPAs across the transition to middle school. Journal of Educational Psychology, 103, 282-295. doi:10.1037/a0023312

Beran, T. (2009). Correlates of peer victimization and achievement: An exploratory model. Psychology in the Schools, 46, 348-361. doi:10.1002/pits.20380

Bjorklund, D. F., \& Hawley, P. H. (2014). Aggression grows up: Looking through an evolutionary developmental lens to understand the causes and consequences of human aggression. In T. K. Shackelford \& R. D. Hansen (Eds.), Evolutionary psychology. The evolution of violence (pp. 159-186). New York, NY, US: Springer Science + Business Media. doi:10.1007/978-1-4614-9314-3_9 
Bollmer, J. M., Milich, R., Harris, M. J., \& Maras, M. A. (2005). A friend in need: The role of friendship quality as a protective factor in peer victimisation and bullying. Journal of Interpersonal Violence, 20, 701-712. doi:10.1177/0886260504272897

Boman, J. H., Krohn, M. D., Gibson, C. L., \& Stogner, J. M. (2012). Investigating friendship quality: An exploration of self-control and social control theories' friendship hypotheses. Journal of Youth and Adolescence, 41, 1526-1540. doi.org/10.1007/s10964-012-9747-x

Boulton, M. J., Trueman, M., \& Flemington, I. (2002). Associations between secondary school pupils' definitions of bullying, attitudes towards bullying, and tendencies to engage in bullying: Age and sex differences. Educational Studies, 28(4), 353-370. doi:10.1080/0305569022000042390

Bradshaw, C. P., Pas, E. T., Bottiani, J. H., Debnam, K. J., Reinke, W. M., Herman, K. C., \& Rosenberg, M. S. (2018). Promoting cultural responsivity and student engagement through Double Check coaching of classroom teachers: An efficacy study. School Psychology Review, 47(2), 118-134. doi:10.17105/SPR-2017-0119.V47-2

Bronfenbrenner, U., \& Morris, P. A. (1998). The ecology of developmental process. In P. H. Mussen, \& Wikessen. (Eds.), Handbook of child psychology, Vol. 1 (pp. 993-1028). New York: Wiley \& Sons.

Chen, J. A. (2012). Implicit theories of ability, epistemic beliefs, and science motivation: A person-centred approach. Learning and Individual Differences, 22, 724-735. doi:10.1016/j.lindif.2012.07.013

Chen, X., \& Graham, S. (2015). Cross-ethnic friendships and intergroup attitudes among Asian American adolescents. Child Development, 86, 749-764. doi:10.1111/cdev.12339 
Chung-Hall, J., \& Chen, X. (2009). Aggressive and prosocial peer group functioning: Effects on children's social, school, and psychological adjustment. Social Development, 19, 659680. doi:10.1111/j.1467-9507.2009.00556.x

Collins, L. M., Schafer, J. L., \& Kam, C. M. (2001). A comparison of inclusive and restrictive strategies in modern missing data procedures. Psychological Methods, 6(4), 330-351.

Crosnoe, R., Cavanagh, S., \& Elder, G. H. (2003). Adolescent friendships as academic resources: The intersection of friendship, race, and school disadvantage. Sociological Perspectives, 46(3), 331-352. doi:10.1525/sop.2003.46.3.331

DeCuir-Gunby, J. T., \& Schutz, P. A. (2014). Researching race within educational psychology contexts. Educational Psychologist, 49(4), 244-260. doi:10.1080/00461520.2014.957828

Dishion, T. J., \& Tipsord, J. M. (2011). Peer contagion in child and adolescent social and emotional development. Annual Review of Psychology, 62, 189-214. doi:10.1146/annurev.psych.093008.100412

Durlak, J. A., Weissberg, R. P., Dymnicki, A. B., Taylor, R. D., \& Schellinger, K. B. (2011). The impact of enhancing students' social and emotional learning: A meta-analysis of schoolbased universal interventions. Child Development, 82, 405-432. doi:10.1111/j.14678624.2010.01564.x

Espelage, D. L., Hong, J. S., Rao, M. A., \& Low, S. (2013). Associations between peer victimisation and academic performance. Theory into Practice, 52(4), 233-240. doi:10.1080/00405841.2013.829724

Faircloth, B. S., \& Hamm, J. (2005). Sense of belonging among high school students represent 4 ethnic groups. Journal of Youth and Adolescence, 34, 293-309. 
Farmer, T. W., Lines, M. M., \& Hamm, J. V. (2011). Revealing the invisible hand: The role of teachers in children's peer experiences. Journal of Applied Developmental Psychology, 32(5), 247-256. doi:10.1016/j.appdev.2011.04.006

Fox, C. L., \& Boulton, M. J. (2005). The social skills problems of victims of bullying: self, peer and teacher perceptions. British Journal of Educational Psychology, 75, 313-328. doi:10.1348/000709905X25517

Fredricks, J. A., Blumenfeld, P. C., \& Paris, A. H. (2004). School engagement: Potential of the concept, state of the evidence. Review of Educational Research, 74, 59-109. doi: $10.3102 / 00346543074001059$

French, D. C., \& Conrad, J. (2001). School dropout as predicted by peer rejection and antisocial behavior. Journal of Research on Adolescence, 11, 225-244. doi:10.1111/15327795.00011

Furrer, C. J. (2010). Capturing the friendship context with a collective property: Friendship group engagement vs. disaffection. Journal of Adolescence, 33, 853-867. doi:10.1016/j.adolescence.2010.07.003

Furrer, C., \& Skinner, E. A. (2003). Sense of relatedness as a factor in children's academic engagement and performance. Journal of Educational Psychology, 95, 148-162. doi:10.1037/0022-0663.95.1.148

Furrer, C. J., Skinner, E. A., \& Pitzer, J. R. (2014). The influence of teacher and peer relationships on students' classroom engagement and everyday resilience. In D. J. Shernoff \& J. Bempechat (Eds.), National Society for the Study of Education Yearbook. Engaging Youth in Schools: Empirically-Based Models to Guide Future Innovations, vol. 113, (pp. 101-123). Columbia University: Teacher's College. 
Geiser, S., \& Santelices, M. V. (2007). Validity of high-school grades in predicting student success beyond the freshman year: High-school record vs. standardized tests as indicators of four-year college outcomes. Research \& Occasional Paper Series: CSHE. 6.07. Center for Studies in Higher Education. University of California, Berkeley.

Gillies, R. M. (2003). The behaviors, interactions, and perceptions of junior high school students during small-group learning. Journal of Educational Psychology, 95, 137-147. doi:10.1037/0022-0663.95.1.137

Graham, S. \& Taylor, A. Z. (2002). Ethnicity, gender, and the development of achievement values. In J. S. Eccles \& A. Wigfield (Eds.), Development of achievement motivation. A volume in the educational psychology series (pp. 121-146). San Diego, CA, US: Academic Press.

Gray, D. L., Hope, E. C., \& Matthews, J. S. (2018). Black and belonging at school: A case for interpersonal, instructional, and institutional opportunity structures. Educational Psychologist, 53(2), 97-113.

Hawley, P. H., Little, T. D., \& Card, N. A. (2007). The allure of a mean friend: Relationship quality and process of aggressive adolescents with prosocial skills. International Journal of Behavioral Development, 31(2), 170-180. doi:10.1177/0165025407074630

Hawley, P. H., Little, T. D., \& Pasupathi, M. (2002). Winning friends and influencing peers: Strategies of peer influence in late childhood. International Journal of Behavioral Development, 26(5), 466-474. doi:10.1080/01650250143000427

Juvonen, J., Espinoza, G., \& Knifsend, C. (2012). The role of peer relationships in student academic and extracurricular engagement. In S. L. Christenson, A. L. Reschly, \& C. Wylie (Eds.), Research on student engagement (pp. 387-401). New York, NY: Springer. 
Kindermann, T. A. (2007). Effects of naturally existing peer groups on changes in academic engagement in a cohort of sixth graders. Child Development, 78, 1186-1203. doi:10.1111/j.1467-8624.2007.01060.x

Kingery, J. N., \& Erdley, C. A. (2007). Peer experiences as predictors of adjustment across the middle school transition. Education and Treatment of Children, 30, 73-88.

Kretschmer, T., Sentse, M., Meeus, W., Verhulst, F. C., Veenstra, R., \& Oldehinkel, A. J. (2016). Configurations of adolescents' peer experiences: Associations with parent-child relationship quality and parental problem behavior. Journal of Research on Adolescence, 26, 474-491. doi:10.1111/jora.12206

Kurdek, L. A., \& Sinclair, R. J. (2000). Psychological, family, and peer predictors of academic outcomes in first-through fifth-grade children. Journal of Educational Psychology, 92(3), 449-457. doi:10.1037/0022-0663.92.3.449

La Freniere, P., \& Charlesworth, W. R. (1983). Dominance, attention, and affiliation in a preschool group: A 9-month longitudinal study. Ethology and Sociobiology, 4, 55-67.

La Greca, A. M., \& Harrison, H. M. (2005). Adolescent peer relations, friendships, and romantic relationships: Do they predict social anxiety and depression? Journal of Clinical Child and Adolescent Psychology, 34(1), 49-61. doi:10.1207/s15374424jccp3401_5

Lease, A. M., Kennedy, C. A., \& Axelrod, J. L. (2002). Children's social constructions of popularity. Social Development, 11, 87-109.

Legault, L., Green-Demers, I., \& Pelletier, L. (2006). Why do high school students lack motivation in the classroom? Toward an understanding of academic amotivation and the role of social support. Journal of Educational Psychology, 98, 567-582. doi:10.1037/0022-0663.98.3.567 
Lo, Y., Mendell, N. R., \& Rubin, D. B. (2001). Testing the number of components in a normal mixture. Biometrika, 88, 767-778. doi:10.1093/biomet/88.3.767

Loveland, J. M., Lounsbury, J. W., Welsh, D., \& Buboltz, W. C. (2007). The validity of physical aggression in predicting adolescent academic performance. British Journal of Educational Psychology, 77, 167-176.

Marsh, H. W., Lüdtke, O., Trautwein, U., \& Morin, A. J. (2009). Classical latent profile analysis of academic self-concept dimensions: Synergy of person-and variable-centred approaches to theoretical models of self-concept. Structural Equation Modeling, 16(2), 191-225. doi:10.1080/10705510902751010

Martin, A. J., \& Dowson, M. (2009). Interpersonal relationships, motivation, engagement, and achievement: Yields for theory, current issues, and educational practice. Review of Educational Research, 79, 327-365. doi:10.3102/0034654308325583

Martin, A. J., \& Marsh, H. W. (2009). Academic resilience and academic buoyancy: Multidimensional and hierarchical conceptual framing of causes, correlates and cognate constructs. Oxford Review of Education, 35, 353-370. doi:10.1080/03054980902934639

Matthews, J. S. (2014). Multiple pathways to identification: Exploring the multidimensionality of academic identity formation in ethnic minority males. Cultural Diversity and Ethnic Minority Psychology, 20(2), 143-155.

Matthews, J. S., Banerjee, M., \& Lauermann, F. (2014). Academic identity formation and motivation among ethnic minority adolescents: The role of the "self" between internal and external perceptions of identity. Child Development, 85, 2355-2373. doi:10.1111/cdev.12318 
Meece, J. L., Glienke, B. B., \& Askew, K. (2009). Gender and motivation. In K. Wentzel \& A. Wigfield (Eds.), Handbook of motivation at school (pp. 411-431). New York: Routledge.

Muthén, L. K., \& Muthén, B. O. (1998-2011). Mplus User's Guide. Sixth Edition. Los Angeles, CA: Muthén \& Muthén.

Nakamoto, J. and Schwartz, D. 2010. Is peer victimization associated with academic achievement? A meta-analytic review. Social Development, 19, 221-242. doi:10.1111/j.1467-9507.2009.00539.x

Nylund, K. L., Asparouhov, T., \& Muthén, B. (2007). Deciding on the number of classes in latent class analysis and growth mixture modeling: A Monte Carlo simulation study. Structural Equation Modeling: A Multidisciplinary Journal, 14, 535-569. doi:10.1080/10705510701575396

Orpinas, P., \& Frankowski, R. (2001). The Aggression Scale: A self-report measure of aggressive behavior for young adolescents. Journal of Early Adolescence, 21, 50-67. doi:10.1177/0272431601021001003

Osborne, A. B. (1996). Practice into theory into practice: Culturally relevant pedagogy for students we have marginalized and normalized. Anthropology \& Education Quarterly, 27(3), 285-314. doi:10.1525/aeq.1996.27.3.04x0351m

Parker, J. G., \& Asher, S. R. (1993). Friendship and friendship quality in middle childhood: Links with peer group acceptance and feelings of loneliness and social dissatisfaction. Developmental Psychology, 29, 611-621. doi:10.1037/0012-1649.29.4.611

Perry, D. G., \& Pauletti, R. E. (2011). Gender and adolescent development. Journal of Research on Adolescence, 21(1), 61-74. doi:10.1111/j.1532-7795.2010.00715.x 
Popp, D., Laursen, B., Kerr, M., Stattin, H.,\& Burk, W. J. (2008). Modeling homophily over time with an actor-partner interdependence model. Developmental Psychology, 44, 10281039. doi:10.1037/0012-1649.44.4.1028

Ricard, N. C., \& Pelletier, L. G. (2016). Dropping out of high school: The role of parent and teacher self-determination support, reciprocal friendships and academic motivation. Contemporary Educational Psychology, 44-45, 32-40.

Rose, A. J., \& Rudolph, K. D. (2006). A review of sex differences in peer relationship processes: Potential trade-offs for the emotional and behavioral development of girls and boys. Psychological Bulletin, 132(1), 98-131. doi:10.1037/0033-2909.132.1.98

Rubin, K. H., Bukowski, W. M., \& Parker, J. G. (2006). Peer interactions, relationships, and groups. In N. Eisenberg (Ed.) Handbook of child psychology: Vol 3. Social, emotional, and personality development (pp. 571-645). Hoboken, NJ: Wiley. doi:10.1002/9780470147658.chpsy0310

Rubin, K. H., Fredstrom, B. \& Bowker, J. (2008). Future directions in. . . friendship in childhood and early adolescence. Social Development, 17, 1085-1096. doi:10.1111/j.14679507.2007.00445.x

Ryan, A. M. (2001). Peer group as a context for the development of young adolescent motivation and achievement. Child Development, 72, 1135-1150. doi:10.1111/1467-8624.00338

Scholte, R. H. J., van Lieshout, C. F. M., \& van Aken, M. A. G. (2001). Perceived relational support in adolescence: Dimensions, configurations, and adolescent adjustment. Journal of Research on Adolescence, 11(1), 71-94. doi:10.1111/1532-7795.00004

Schwartz, D., Gorman, A.H., Dodge, K.A., Pettit, G. S., \& Bates, J. E. (2008). Friendships with peers who are low or high in aggression as moderators of the link between peer 
victimization and declines in academic functioning. Journal of Abnormal Child Psychology, 36, 719-730. doi:10.1007/s10802-007-9200-х

Selfhout, M.H.W., Branje, S.J.T., \& Meeus, W.H.J. (2009). Developmental trajectories of perceived friendship intimacy, constructive problem solving, and depression from early to late adolescence. Journal of Abnormal Child Psychology, 37, 251-264. doi:10.1007/s10802-008-9273-1

Skinner, E. A., Furrer, C. J., Marchand, G. C., \& Kindermann, T. A. (2008). Engagement and disaffection in the classroom: Part of a larger motivational dynamic? Journal of Educational Psychology, 100, 765-781. doi:10.1037/a0012840

Skinner, E. A., Kindermann, T. A., \& Furrer, C. F. (2009). A motivational perspective on engagement and disaffection: Conceptualization and assessment of children's behavioral and emotional participation in academic activities in the classroom. Educational and Psychological Measurement, 69, 493-525. doi:10.1177/0013164408323233

Slavich, G. M., \& Zimbardo, P. G. (2012). Transformational teaching: Theoretical underpinnings, basic principles, and core methods. Educational Psychology Review, 24(4), 569-608. doi:10.1007/s10648-012-9199-6

Smith, A. L., Ullruch-French, S., Walker II, E., \& Hurley, K. S. (2006). Peer relationship profiles and motivation in youth sport. Journal of Sport \& Exercise Psychology, 28, 362-382.

Taylor, A. Z., \& Graham, S. (2007). An examination of the relationship between achievement values and perceptions of barriers among low-SES African American and Latino students. Journal of Educational Psychology, 99(1), 52-64. 
Usher, E. L. (2018). Acknowledging the whiteness of motivation research: Seeking cultural relevance. Educational Psychologist, 53(2), 131-144. doi:10.1080/00461520.2018.1442220

Vaillancourt, T., Hymel, S., \& McDougall, P. (2003). Bullying is power. Journal of Applied School Psychology, 19(2), 157-176. doi:10.1300/J008v19n02_10

von Eye, A., \& Bogat, A. (2006). Person-oriented and variable-oriented research: Concepts, results, and development. Merrill-Palmer Quarterly, 52(3), 390-420. doi:10.1353/mpq.2006.0032

Wang, M-T., \& Eccles, J. S. (2012). Social support matters: Longitudinal effects of social support on three dimensions of school engagement from middle to high school. Child Development, 83, 877-895. doi:10.1111/j.1467-8624.2012.01745.x

Wellborn, J. G. (1991). Engaged and disaffected action: The conceptualization and measurement of motivation in the academic domain (Unpublished doctoral dissertation). University of Rochester, New York.

Wentzel, K. R. (1999). Social-motivational processes and interpersonal relationships: Implications for understanding motivation at school. Journal of Educational Psychology, 91, 76-97. doi:10.1037/0022-0663.91.1.76

Wentzel, K. R., Barry, C. M., \& Caldwell, K. A. (2004). Friendships in middle school: Influences on motivation and school adjustment. Journal of Educational Psychology, 96(2), 195-203. doi:10.1037/0022-0663.96.2.195

Yuan, K-H., \& Bentler, P. M. (2000). Three likelihood-based methods for mean and covariance structure analysis with nonnormal missing data. Sociological Methodology, 30(1), 165200. doi:10.1111/0081-1750.00078 
Zee, M., \& Koomen, H. M. (2016). Teacher self-efficacy and its effects on classroom processes, student academic adjustment, and teacher well-being: A synthesis of 40 years of research. Review of Educational Research, 86, 981-1015. doi:10.3102/0034654315626801 
Table 1. Descriptives, correlations, and reliability statistics

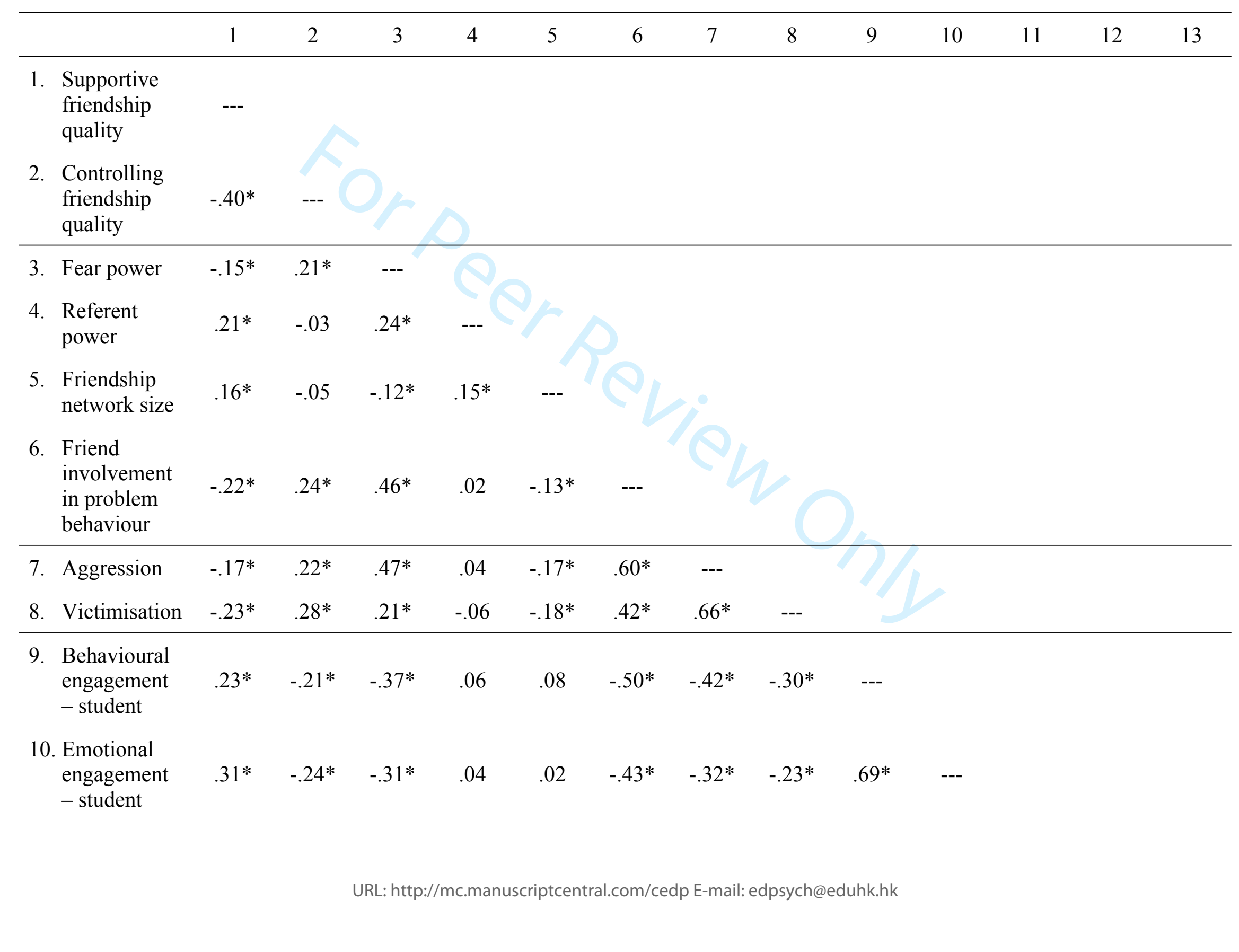




\begin{tabular}{|c|c|c|c|c|c|c|c|c|c|c|c|c|c|}
\hline & 1 & 2 & 3 & 4 & 5 & 6 & 7 & 8 & 9 & 10 & 11 & 12 & 13 \\
\hline $\begin{array}{l}\text { 11. Behavioural } \\
\text { engagement } \\
\text { - teacher }\end{array}$ & $.13 *$ & -.01 & $-.36^{*}$ & -.06 & $.25^{*}$ & $-.38^{*}$ & $-.42 *$ & $-.34 *$ & $.32 *$ & $.15^{*}$ & --- & & \\
\hline $\begin{array}{l}\text { 12. Emotional } \\
\text { engagement } \\
\text { - teacher }\end{array}$ & $.20 *$ & -.10 & $-.34 *$ & -.05 & $.34 *$ & $-.34^{*}$ & $-.34 *$ & $-.32 *$ & $.33 *$ & $.20 *$ & $.74 *$ & --- & \\
\hline 13. GPA & .06 & -.09 & $-.31 *$ & -.06 & $.26^{*}$ & $-.33 *$ & $-.33 *$ & $-.28 *$ & $.49 *$ & $.32 *$ & $.41^{*}$ & $.30 *$ & --- \\
\hline Mean $(S D)$ & $\begin{array}{c}3.34 \\
(0.61)\end{array}$ & $\begin{array}{c}1.49 \\
(0.48)\end{array}$ & $\begin{array}{c}1.67 \\
(0.66)\end{array}$ & $\begin{array}{c}2.49 \\
(0.83)\end{array}$ & $\begin{array}{c}3.31 \\
(2.87)\end{array}$ & $\begin{array}{c}0.89 \\
(0.43)\end{array}$ & $\begin{array}{c}0.66 \\
(0.72)\end{array}$ & $\begin{array}{c}0.55 \\
(0.63)\end{array}$ & $\begin{array}{c}2.99 \\
(0.59)\end{array}$ & $\begin{array}{c}3.08 \\
(0.55)\end{array}$ & $\begin{array}{c}2.88 \\
(0.68)\end{array}$ & $\begin{array}{c}3.02 \\
(0.59)\end{array}$ & $\begin{array}{c}3.12 \\
(0.72)\end{array}$ \\
\hline Alpha & .88 & .75 & .64 & .80 & -- & .86 & .89 & .82 & .83 & .84 & .88 & .89 & --- \\
\hline
\end{tabular}

$* p<.05$ 
Table 2. Fit indices for comparing latent profiles

\begin{tabular}{lllllll}
\hline No. Group & $\begin{array}{l}\text { No. } \\
\text { Parameters }\end{array}$ & AIC & BIC & $p$ LMR & $\begin{array}{l}\text { Smallest } \\
\text { class count } \\
\text { (prop) }\end{array}$ & Entropy \\
\hline 2 & 27 & 6744.23 & 6854.64 & - & $103(.23)$ & 0.84 \\
3 & 38 & 6574.52 & 6729.90 & 0.02 & $40(.09)$ & 0.82 \\
4 & 49 & 6490.33 & 6690.70 & 0.64 & $29(.07)$ & 0.85 \\
5 & 60 & 6429.91 & 6675.25 & 0.18 & $22(.05)$ & 0.76 \\
\hline
\end{tabular}

Note. $\mathrm{AIC}=$ Akaike information criteria. $\mathrm{BIC}=$ Bayesian information criteria.

$p$ LMR $=p$ values for the comparison of $k$ versus $k-1$ classes. 
Table 3. Profile descriptives for peer system dimensions

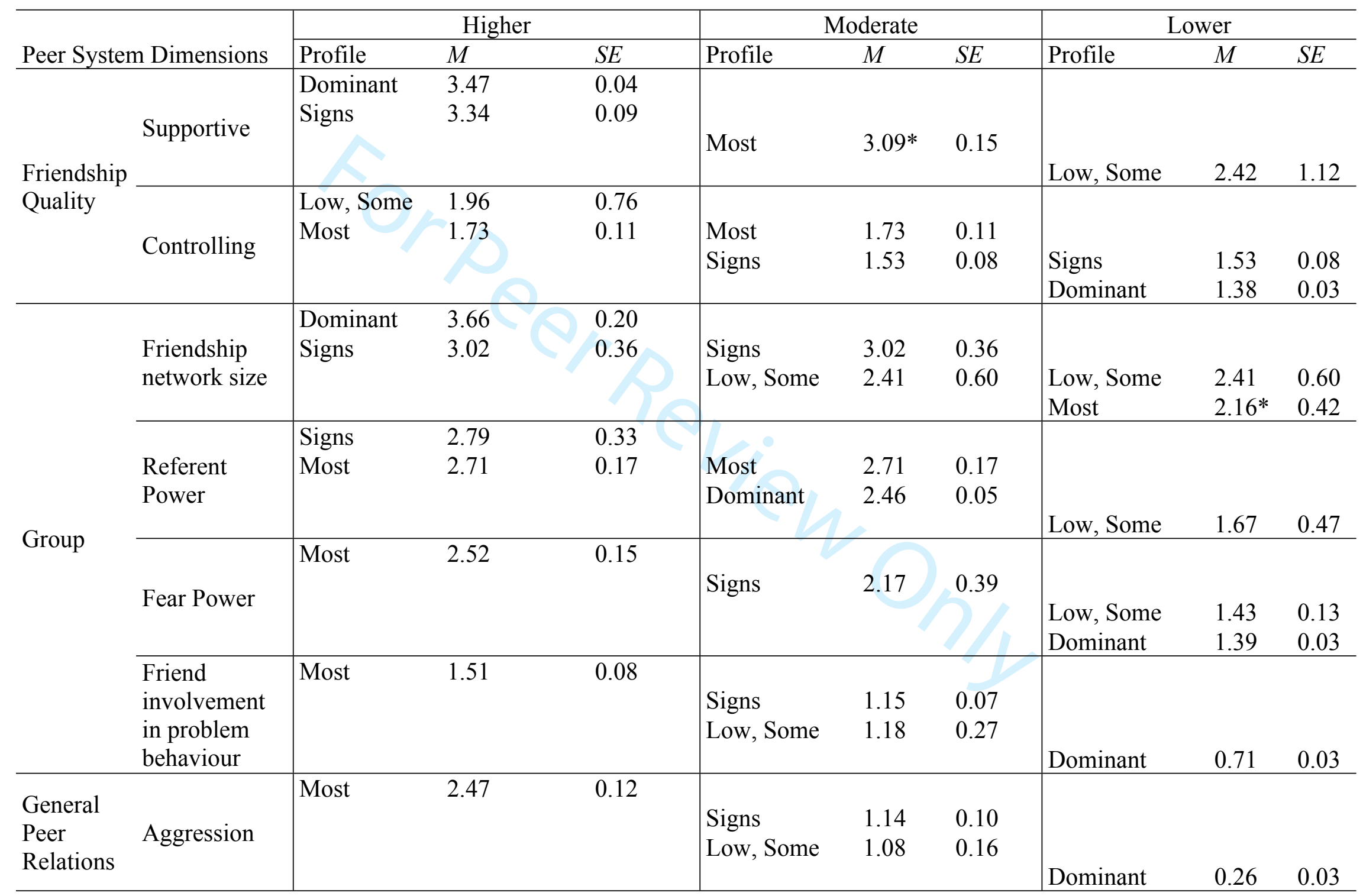




\begin{tabular}{|c|c|c|c|c|c|c|c|c|c|}
\hline \multirow[b]{2}{*}{ Peer System Dimensions } & \multicolumn{3}{|c|}{ Higher } & \multicolumn{3}{|c|}{ Moderate } & \multicolumn{3}{|c|}{ Lower } \\
\hline & Profile & $M$ & $S E$ & Profile & $M$ & $S E$ & Profile & $M$ & $S E$ \\
\hline Victimisation & $\begin{array}{l}\text { Most } \\
\text { Low, Some }\end{array}$ & $\begin{array}{l}1.75 \\
1.42\end{array}$ & $\begin{array}{l}0.15 \\
0.24\end{array}$ & Signs & 0.65 & 0.26 & & & \\
\hline & & & & & & & Dominant & 0.30 & 0.03 \\
\hline
\end{tabular}

Notes: Signs = Signs of Challenging Peer Relations; Most = Most Challenging Peer Relations; Low, Some = Low Friend Quality, Some Challenging Peer Relations. Profiles that differ significantly $p<.05$ are in separate groupings (Higher $=$ highest means;

Moderate $=$ moderate means; Lower $=$ lowest means). If a profile is in two groupings, it was not statistically different than the profiles in both groupings.

* Signs vs. Most was marginally significant, $p<.10$ 
Figure 1. Peer system profiles

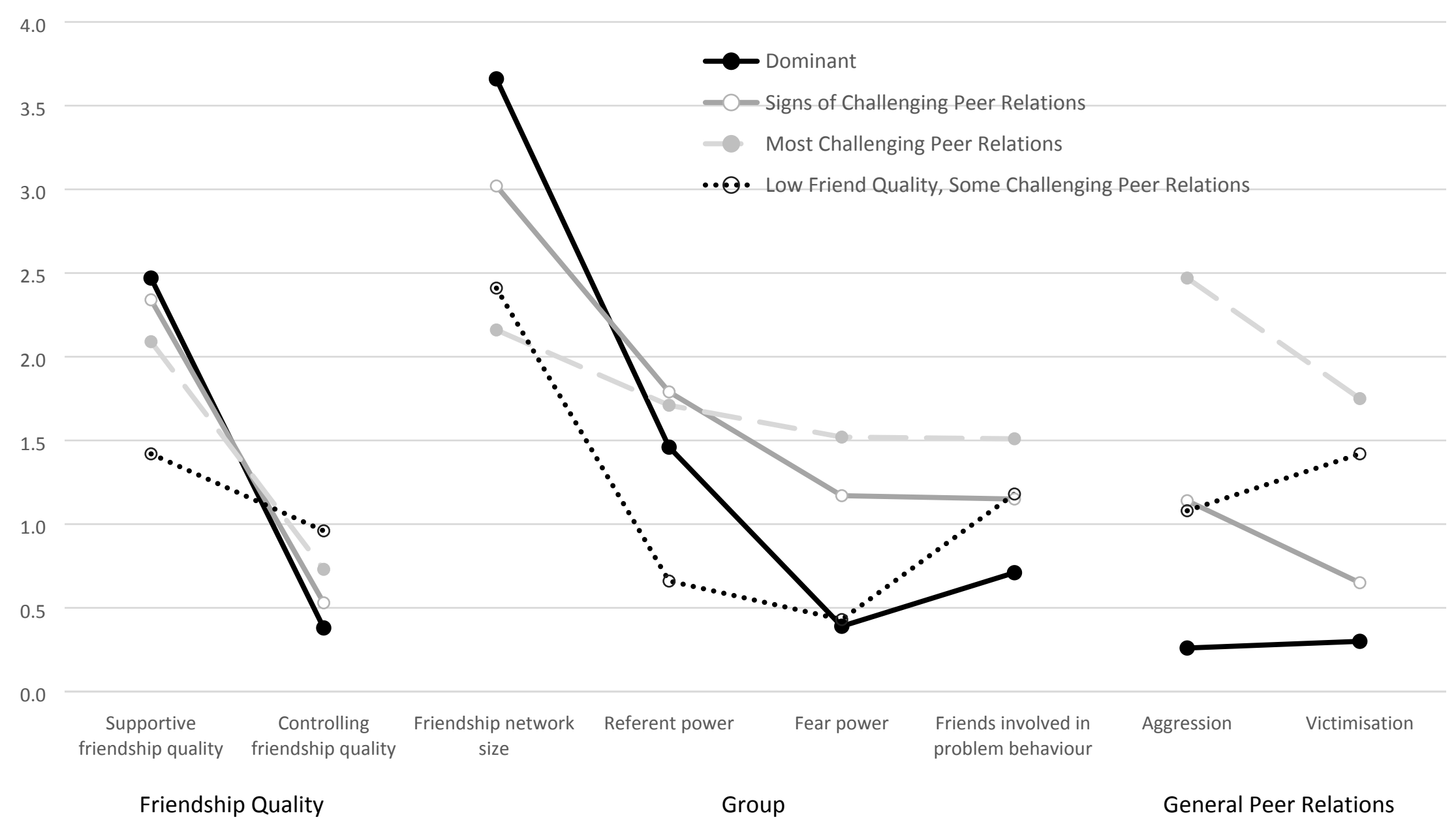

Note. Scores for constructs measured on a scale starting with 1 (supportive and controlling friendship quality, friends involved in problem behavior, fear and referent power) were adjusted down by 1 point for visual consistency. 